\title{
Ecosystem services in environmental sustainability: a formalized approach using UML
}

\author{
$\underline{\text { P.A. Khaiter }}^{\text {a }}$ and M.G. Erechtchoukova ${ }^{a}$ \\ ${ }^{a}$ School of Information Technology, Faculty of Liberal Arts and Professional Studies, York University, \\ Toronto, Canada \\ Email: pkhaiter@yorku.ca
}

\begin{abstract}
Ecological systems generate diverse services that are vital for human well-being and socioeconomic development. Ecosystem services are a key notion for the idea of sustainable environmental development. A practical utilization of this concept of sustainability requires a mechanism whereby all the goods and services generated by ecosystems are adequately quantified, valuated and incorporated in the decision-making process. Each of these tasks is substantially non-trivial. To deal with the named complexity, an adequate theoretical framework and a sophisticated information system have to be in place for the use by stakeholders of environmental sustainability.
\end{abstract}

A theoretical framework for environmental sustainable management and its further extension on the basis of a meta-modeling approach have been suggested in our prior publications. As the next step, we need to build an information system implementing the main elements of the framework in corresponding software components.

In this paper, we are suggesting a formalized approach to the entire process of sustainable environmental management on the basis of the Unified Modeling Language (UML). UML is a standardized graphical language being used in object-oriented software engineering for specifying, documenting and visual modeling of an IT project's artifacts or components within a wide range of applications. With the three groups of graphical models (i.e., functional, object and dynamic), UML is aimed to provide a standard notation and describe different aspects of a software project. We demonstrate the ways, in which UML can be applied in the information systems development for the needs of environmental management and protection. The constituting software blocks of an environmental information system implementing the framework are presented by the following UML graphical models:

- overall system architecture is depicted as a UML package diagram;

- contents of the Ecosystem package are shown as a UML use-case diagram;

- activities of the Monitoring package are shown in the notation of a UML use-case diagram

- the Modeling package is presented as a UML component diagram;

- internal steps within the Modeling natural dynamics module are shown as a UML use-case diagram;

- logic of the Modeling anthropogenic dynamics module is demonstrated as a UML use-case diagram;

- internal steps of the Valuation package are shown as a UML use-case diagram; and

- flow of operations within the Management package is presented as a UML activity diagram.

For many years, UML has been successfully utilized in the systems development life cycles of business-type IT projects. It is supported by multiple commercial and free CASE-tools, including those featuring reverseand round-trip engineering.

At the same time, despite obvious advantages, applications of UML in the design of environmental information systems remain rather limited. While UML has not been widely adopted and used in environmental modeling and software design, it is reasonable to expect growing interest towards UML in the field as a tool to combine the power of visual and simulation modeling and to facilitate automated construction and synthesis of environmental information systems.

The paper is also intended to inspire and shape the discussion within the session on "Models, Methods, Techniques and Tools in Quantifying Ecosystem Services and Environmental Sustainability".

Keywords: Environmental management, ecosystem services, Unified Modeling Language (UML) 
Khaiter and Erechtchoukova, Ecosystem services in environmental sustainability: a formalized approach...

\section{INTRODUCTION}

In the most generic sense, environmental sustainability can be understood as maintaining natural capital and resources (Goodland, 1995). The frequently cited Brundtland report Our Common Future (1987) defined sustainable management as "development that meets the needs of present generations without compromising the ability of future generations to meet their needs." Neither of these definitions specifies a quantitative criterion or measure of sustainability to be used in practice of environmental management.

Human survival depends on the collective services provided by Earth's interacting ecosystems. The UN-led Millennium Ecosystem Assessment initiative (MA, 2005) classified ecosystem services in four broad groups: provisioning, such as the production of food and water; regulating, such as the control of climate and disease; supporting, such as nutrient cycles and crop pollination; and cultural, such as spiritual and recreational benefits.

In our view, the very idea of sustainable environmental development is best approached on the basis of ecosystem services. It requires a mechanism whereby all the goods and services generated by ecosystems are adequately quantified, valuated and incorporated in the decision-making process (Khaiter and Erechtchoukova, 2007). Each of these tasks is substantially non-trivial:

- Quantities of ecosystem goods and services are formed under a complex interplay of natural and anthropogenic factors. Their prediction is only possible in computer experiments with process-based simulation models of the phenomena.

- There are no common techniques to value ecosystem services economically, socially, culturally or environmentally. In particular, many services have no market values, and their pricing can be done through some indirect, predominantly artificial, exercises.

- Decision-making, as a formalized process, becomes quite complex from both mathematical and computational perspectives.

To successfully deal with the aforementioned challenges, an adequate theoretical framework and a sophisticated information system have to be offered to the stakeholders of environmental sustainability.

\section{METHODOLOGY}

\subsection{Framework}

A theoretical framework for quantifying ecosystem services in environmental management scenarios has been suggested and described in our earlier publication (Khaiter and Erechtchoukova, 2010). The framework was further extended on the basis of a meta-modeling approach with the inclusion of the valuation and decision-making tasks at the upper meta-modeling levels (Khaiter and Erechtchoukova, 2012).

A practical implementation of the framework, however, requires an information system realizing the main elements of the framework in corresponding software components and enabling its practical use by the policy- and decision-makers as well as by the broader stakeholders. In this paper, we present the main constituting software blocks of the framework in the UML notation.

\subsection{Unified Modeling Language (UML)}

The Unified Modeling Language (UML) is a standardized graphical language being used in object-oriented software engineering for specifying, documenting and visual modeling of an IT project's artifacts or components (Fowler, 2004; Rumbaugh, 1999). As a de facto standard and the primary modeling tool (Booch, 2007), UML has been utilized in the systems development life cycles of business-type IT projects for many years (Satzinger, 2012). Over time, information systems have overstepped their original limits of business applications and penetrated into non-business areas of human activities, such as, environmental protection and management. Applications of UML in the design of environmental information systems remain rather limited (e.g. Heisel et al., 2008; Parajorgji and Schatar, 2004; Pinet et al., 2007). It appears that this area of research is very promissing as it allows combining the power of visual and simulation modeling.

In the subsequent section of the paper, we present a formalized approach to the entire process of sustainable environmental management and to implementing it environmental information system on the basis of UML. 
Khaiter and Erechtchoukova, Ecosystem services in environmental sustainability: a formalized approach...

\section{RESULTS}

\subsection{Overall architecture}

In accordance with the framework definition, it consists of five main building blocks. A UML notation of a package diagram, representing key software components (Rumbaugh, 1999), is used to show each of the constituting blocks: Ecosystem, Monitoring, Modeling, Valuation and Management (Figure 1). The blocks are discussed in the relevant sub-sections.

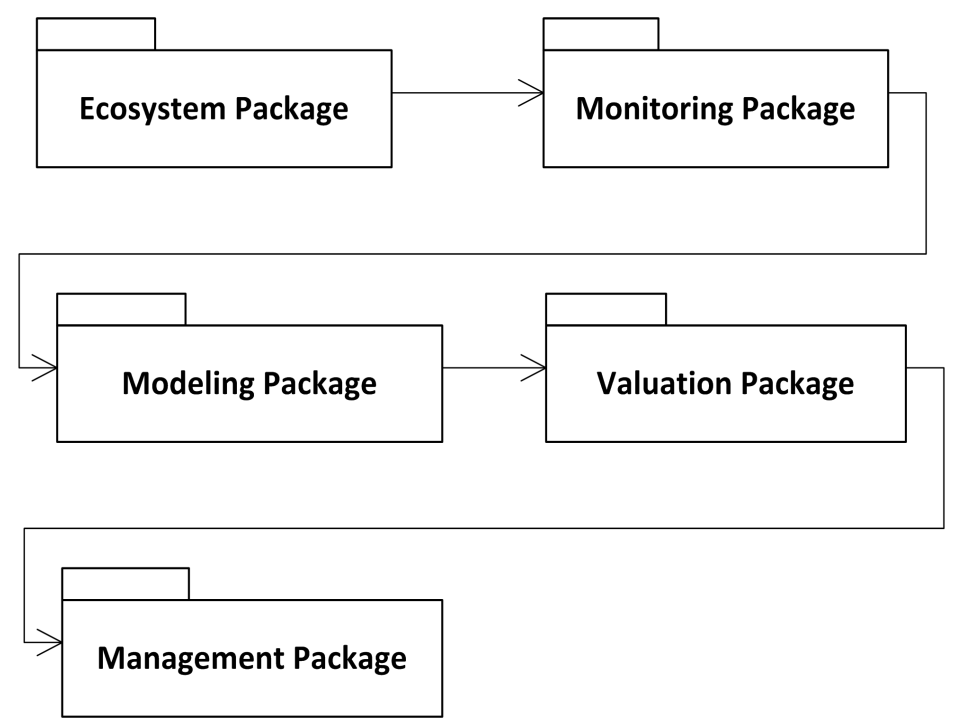

Figure 1. Overall system architecture using UML package diagram.

\subsection{Ecosystem Package}

Any study of the ecosystem services assumes the specification of the ecosystems affected by the planned activities. Following general systems theory (von Bertalanffy, 1969) and classical ecology (Mueller, 1997; Odum, 1983), for each ecosystem, we need to delineate its boundary from the external environment, interfaces (i.e., inputs and outputs), components and their composition and interrelationships (i.e., the structure), and processes which govern the ecosystem functioning.

As an adequate description of an ecosystem $(E)$, we suggest a tuple which includes a set $\{C\}$ of biotic and abiotic components and factors (i.e., ecosystem composition), a set $\{S\}$ of their particular assemblages and interrelationships (i.e., ecosystem structure), a set $\{P\}$ of ecosystem parameters designating quantitative values of the ecological processes involving components and interactions between them, a set $\{\operatorname{In}\}$ of environmental inputs and a set $\{O u t\}$ of ecosystem outputs:

$$
E=\langle\{I n\},\{C\},\{\mathrm{S}\},\{P\},\{O u t\}\rangle \text {. }
$$

At any given time instant, $t$, the components (or sub-systems) of an ecological system can be represented by a non-negative state vector $\mathbf{x}(t)$ belonging to an $n$-dimensional space:

$$
\mathbf{x}(t)=\left(x_{1}(t), \ldots, x_{n}(t)\right) \in \Omega \subseteq \Re^{n+}, n>1, x_{i}(t) \geq 0 \forall i, t .
$$

The state variables quantitatively designate elements of the set $\{S\}$, i.e. both biotic and abiotic constituents of the ecosystem and their properties, such as richness and density of species or their assemblages, concentrations of organic and inorganic matters and polluting substances, etc. Parameters of the ecosystem, i.e., elements of the set $\{P\}$, are represented by an $m$-dimensional vector:

$\mathbf{p}(t)=\left(p_{1}(t), \ldots, p_{m}(t)\right) \in \mathrm{P} \subseteq \mathfrak{R}^{m}$.

Their natural and anthropogenic dynamics as well as respective stressors have to be understood. These steps involve an interaction of two actors: Ecologist and Modeler. A format of a UML use-case diagram is applied to demonstrate the contents of the Ecosystem package. Due to the space limitations, the diagram will be incorporated into the conference presentation. 
Khaiter and Erechtchoukova, Ecosystem services in environmental sustainability: a formalized approach...

\subsection{Monitoring Package}

Implementation of the framework requires diverse observation data collected in conformity with a certain program. Relevant activities are grouped in the Monitoring package shown in the notation of a UML usecase diagram (Figure 2).

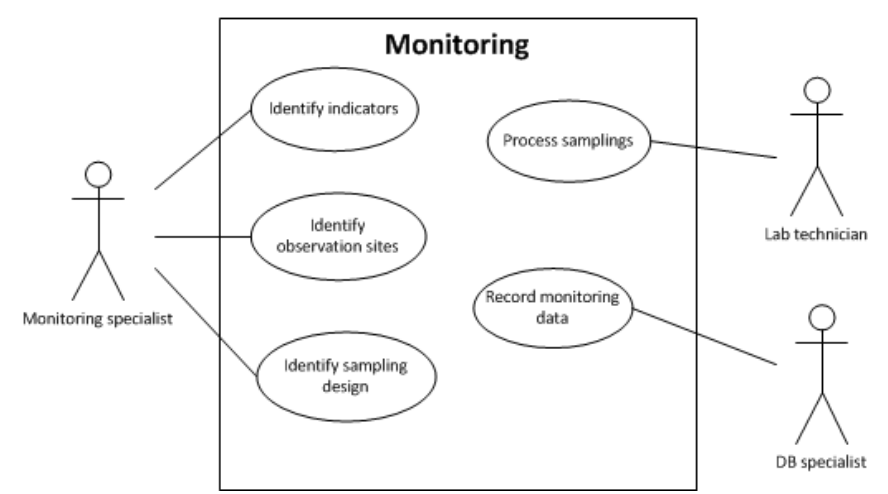

Figure 2. Activities of the Monitoring package shown as UML use-case diagram.

An actor denoted as Monitoring specialist is answerable for identifying a set of indicators, observation sites and sampling design. Processing of samples is performed by the Lab technician actor. The DB specialist actor supports recording of monitoring data in the system.

\subsection{Modeling Package}

The Modeling package consists of modules dealing with Modeling natural dynamics, Modeling anthropogenic dynamics and a module of Quantifying ecosystem services. These modules are represented as the UML components (Figure 3).

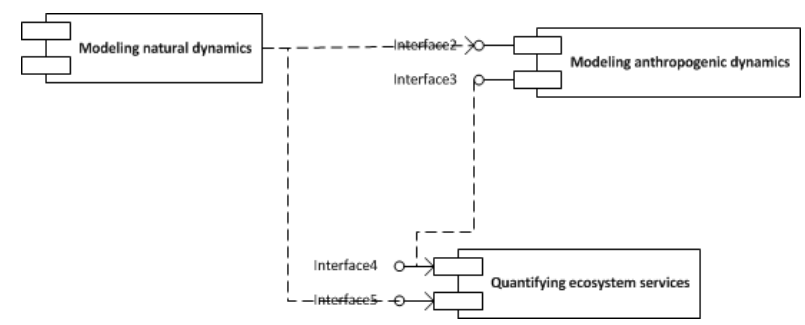

Figure 3. Modules of the Modeling package shown as UML component diagram.

Internal steps in the Modeling natural dynamics module involve the Modeler actor. They are demonstrated on a UML use-case diagram and are largely divided into the model design stage and the model testing stage. The stage of model design includes: (1) development of a conceptual model (i.e., selection of major variables and processes); (2) mathematical description of the conceptual model in the form of equations; (3) parameterization (i.e., determination of quantitative values of model parameters); and (4) coding (i.e., translation of the mathematical equations into computer-based software). The model testing stage involves: (1) simulation runs; (2) verification (i.e., comparison of results obtained from model simulation with values observed in the system); (3) validation (i.e., a proof that the reactions and dynamics generated by the model are similar with the behaviour of the real system); (4) stability study of simulation results (i.e., investigation of model reactions to perturbations of initial values of model variables), mostly in a sense of the Liapunov stability; (5) sensitivity analysis to major parameters (i.e., a series of tests in which the modeler varies the values of model parameters to see the corresponding changes in model outputs); and (6) uncertainty analysis (i.e., a measure of an error in model simulation of given observations due to parameters, state variables and model structure). The diagram will be incorporated into the conference presentation.

The logic of the Modeling anthropogenic dynamics module is depicted as a UML use-case diagram (Figure 4). On the first step, the Ecologist actor determines a particular type of stress caused by a planned human activity. In the interaction with the Modeler actor, it is required to decide on the particular affected state variables and parameters as well as possible structural transformations within the ecosystem. It, in turn, 
Khaiter and Erechtchoukova, Ecosystem services in environmental sustainability: a formalized approach...

enables to define domains of ecosystem structural stability. It has been argued (Khaiter and Erechtchoukova, 2009) that a model is suitable only for a certain domain where the ecosystem maintains its structure and that, generally speaking, a new model has to be built if a structural transformation occurs, though a new model can, to a different extent, inherit certain features of the old one (Pusachenko, 1989).

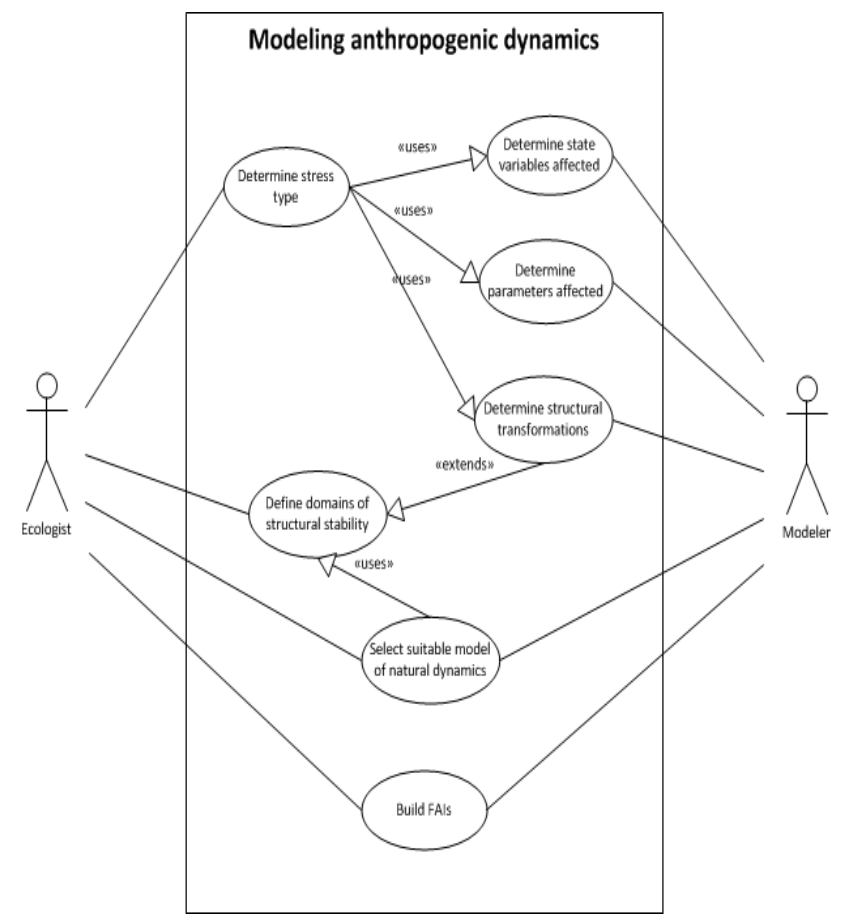

Figure 4. Logic of the Modeling anthropogenic dynamics module shown as UML use-case diagram.

As one of the approaches to the modeling of stress dynamics, we first determine a suitable model of natural dynamics and then construct functions of anthropogenic impact for each affected state variable and for each type of stress (Khaiter, 1991; Pusachenko, 1989), i.e.:

$x_{i}^{\mathrm{A}}=F A I_{i, k} * x_{i}^{\mathrm{N}}, \forall i=1, . ., n ; \forall k=1, . ., K$,

where $x_{i}^{N}$ and $x_{i}^{A}$ are the $i$ th coordinate of the state vector $\mathbf{x}$ before (i.e., natural, untouched state) and after an anthropogenic impact of the $k$ th type, respectively; $F A I_{i, k}$ is the function of anthropogenic impact of the $k$ th type onto the $i$ th coordinate of the state vector $\mathbf{x}$.

The task of the Quantifying ecosystem services module is to produce the physical measures of ecosystem services. As shown in Figure 3, they are computed outputs of either models of natural dynamics or models of anthropogenic dynamics, or a certain composition of both model types.

For example, to quantify hydrological service of forest, it is necessary to estimate a delayed runoff from a given watershed as the difference between slow and quick items of the water budget. When we study the impact of deforestation on this ecosystem service, watersheds with various percentages of forest cover have to be compared, but such "paired" watersheds are not always readily available. To this end, an approach has been suggested (Khaiter, 1993) that is based on a simulation model "Forest hydrology" (SMFH) of the processes of moisture transformation in a forested watershed. The SMFH simulates the processes of forest hydrology, produces the values of the water balance components as outputs, and provides a quantitative assessment of the hydrological service of forest under different management scenarios.

\subsection{Valuation Package}

Any decision-making pertaining to natural resources or environmental systems would certainly involve the valuation issues, because we need to chose from a set of possible alternatives and determine which of them is more preferable than others. The latter cannot be reasonably implemented without attributing some monetary value to a whole spectrum of the ecosystem services or applying broader valuation techniques. As Goulder and Kennedy (1997) state, it always "requires to indicate which alternative is deemed to be worth more." 
Khaiter and Erechtchoukova, Ecosystem services in environmental sustainability: a formalized approach...

Economic assessment of ecosystem services is based on "the central environmental principle of full-cost pricing" (Porter, 1996). However, a competitive or even mutually exclusive nature of the services has to be taken into the consideration. In practical terms, a full set of all the ecosystem services is not an attainable value but rather an ideal one, and a subset of mutually compatible services has to be determined for each planned scenario of human activities. Another problem is that, at the moment, many of the services have no direct market price. From the perspectives of economic theory, they reveal themselves as positive externalities. Valuing of these benefits is a crucial component of a sustainable management. Existing techniques of valuation of ecosystem benefits are summarized in (Khaiter, 2005).

Figure 5 presents the steps in the valuation process in the form of a UML use-case diagram, in which three actors interact: Ecologist, Modeler and Environmental economist.

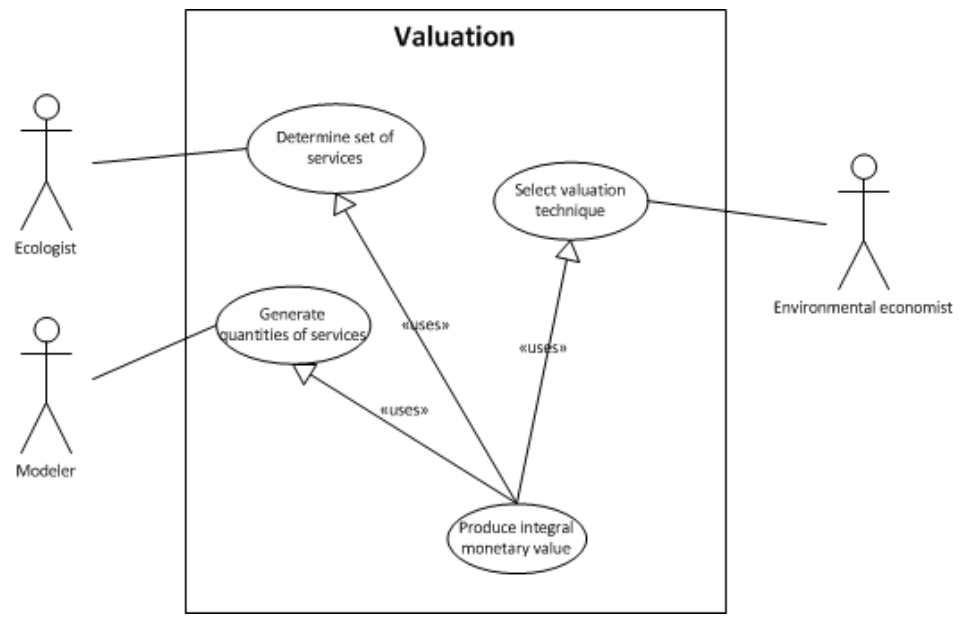

Figure 5. Steps in the valuation process shown as UML use-case diagram.

\subsection{Management Package}

The Management package implements the tasks of optimal control and multi-objective optimization. The flow of operations within the Management package is shown as a UML activity diagram. Due to the space limitations, the diagram will be incorporated into the conference presentation.

\section{DISCUSSION AND CONCLUSIONS}

The overall architecture and the software components of an environmental information system have been described using UML notation. UML is a language for visual modeling in object-oriented software development, representing both static structures and their dynamic behaviour. It is supported by multiple commercial and free CASE-tools, including those featuring reverse and round trip engineering.

Despite its advantages, UML has not been widely adopted and used in environmental modeling and software design. It is reasonable to expect growing interest towards UML in the field as a means to combine the power of visual and simulation modeling and to facilitate automated construction and synthesis of environmental information systems.

\section{ACKNOWLEDGMENTS}

The authors are thankful to the anonymous reviewers for their helpful suggestions and comments on the early version of the manuscript. Part of this work was supported by the Faculty of Liberal Arts and Professional Studies (FLA\&PS) through individual grants to each co-author. Personal thanks to Dr. Martin Singer, Dean of FLA\&PS, for his support of this project. All UML diagrams have been prepared with Microsoft ${ }^{\circledR}$ Visio $^{\circledR}$ Premium 2010.

\section{REFERENCES}

Booch, G., Maksimchuk, A., Engle, M.W., Young, B.J., Conallen, J., and Houston, K.A. (2007). Objectoriented analysis and design with applications, $3^{\text {rd }}$ ed., pp.691. Pearson, Boston. 
Khaiter and Erechtchoukova, Ecosystem services in environmental sustainability: a formalized approach...

Fowler, M. (2004). UML distilled: a brief guide to the standard object modeling language, $3^{\text {rd }}$ ed., pp.176. Pearson, Boston.

Goodland, R. (1995). The concept of environmental sustainability. Annual Review of Ecology and Systematics, 26, 1-24.

Heisel, M., Hartebur, D., Santen, T., and Seifert, D. (2008). Using UML environment models for test case generation. Software Engineering 2008 - Workshopband, Lecture Notes in Informatics. GI.

Khaiter, P.A. (1991). Modeling of anthropogenic dynamics of forest biogeocenoses, pp.24. Znaniye, Kiev.

Khaiter P.A. (1993). Mathematical modeling in the study of the hydrological regime in 'Forest-Watershed' system. Computational Methods in Water Resources. CMP, Southampton, UK, 789-794.

Khaiter, P.A., and Erechtchoukova, M.G. (2007) Environmental assessment of anthropogenic impact through the patterns of ecosystem reactions, The International Journal of Environmental, Cultural, Economic and Social Sustainability, 3(4), 181-190,.

Khaiter P.A., and Erechtchoukova, M.G. (2009). The notion of stability in mathematics, biology, ecology and environmental sustainability, 18th IMACS World Congress - MODSIM09 International Congress on Modelling and Simulation, 13-17 July 2009, Cairns, Australia, B. Anderssen et al. (Eds.), 2265-2271.

Khaiter, P.A., and Erechtchoukova, M.G. (2010). A Model-based quantitative assessment of ecosystem services in the scenarios of environmental management, 2010 International Congress on Environmental Modelling and Software, Fifth Biennial Meeting, 5-8 July 2010, Ottawa, Canada, D. A. Swayne, Y. Wanhong, A. A. Voinov, A. Rizzoli, and T. Filatova (Eds.), 272-279.

Khaiter, P.A., and Erechtchoukova, M.G. (2012). Quantitative assessment of natural and anthropogenic factors in forest carbon sequestration, 2012 International Congress on Environmental Modelling and Software, Sixth Biennial Meeting, 1-5 July 2012, Leipzig, Germany. R. Seppelt, A.A. Voinov, S. Lange, D. Bankamp (Eds.), 2075-2082.

MA (Millennium Ecosystem Assessment). (2005). Ecosystems and human well-being: synthesis, pp.160. Island Press, Washington, D.C.

Mueller, F. (1997). State-of-the-art in ecosystem theory, Ecological Modelling, 100(1-3), 135-161.

Odum, E.P. (1983). Basic ecology, pp.402. Saunders College Publishing, Philadelphia.

Our Common Future / World Commission on Environment and Development (1987), pp.383. Oxford University Press, Oxford.

Papajorgji, P., and Shatar, T.M. (2004). Using the Unified Modeling Language to develop soil water-balance and irrigation-scheduling models. Environmental Modelling and Software, 19(5), 451-459.

Pinet, F., Duboisset, M., and Soulignac, V. (2007). Using UML and OCL to maintain the consistency of spatial data in environmental information systems. Environmental Modelling and Software, 22(8), 12171220.

Porter, G. (1996). Natural Resource Subsidies, Trade and Environment: The Cases of Forests and Fisheries. CIEL Publ., pp.35. http://www.ciel.org/Publications/NaturalResourceSubsidies.pdf (accessed on August 3, 2013).

Pusachenko, Yu.G. (ed.) (1989). Ecosystems in critical states, pp.155. Nauka, Moscow.

Rumbaugh, J., Jacobson, I., and Booch, G. (1999). The Unified Modeling Language reference manual, pp.550. Addison-Wesley, Reading, Massachusetts.

Satzinger, J.W., Jackson, R.B., and Burd, S.D. (2012). Systems analysis and design in a changing world, $6^{\text {th }}$ ed., pp.486. Course Technology, Boston.

von Bertalanffy, L. (1969). General systems theory: foundations, development, applications, pp.289 G. Braziller, New York. 